\title{
Endovascular Embolization of Large Original Internal Carotid Artery Aneurysms: Single-center Experience with 10 Cases and Literature Review
}

Jiro Aoyama, Keigo Shigeta, Shin Sato, Masaya Enomoto, Toshiya Momose, Kyoko Sumiyoshi, Hiroshi Yatsushige, and Takanobu Hayakawa

Objective: We reviewed the treatment results of internal carotid artery (ICA) aneurysms with a maximum diameter of $10 \mathrm{~mm}$ or greater for the future selection of patients with indications for Pipeline Flex (Medtronic, Irvine, CA, USA).

Methods: The treatment methods, treatment effects, complication rate, and retreatment rate were studied in lesions that were treated by coil embolization but are presently considered indications for treatment using Pipeline Flex among the 516 cerebral aneurysms treated at our hospital between July 2009 and May 2016. We also reviewed the literature concerning coil embolization for large and giant aneurysms and examined the results of coil embolization for aneurysms with indications for Pipeline.

Results: The subjects were 10 patients consisting of 5 with asymptomatic unruptured aneurysm, 2 with symptomatic unruptured aneurysm, and 3 patients with recurrence after treatment for ruptured aneurysm. The mean size of the aneurysms was $12.8 \mathrm{~mm}(10.5-17.8 \mathrm{~mm})$, and the mean follow-up period was $49.1 \pm 13.4$ months. The treatments were balloon-assisted coil embolization in eight patients and stent-assisted coil embolization in two patients. None showed postoperative symptomatic ischemic lesions, and the permanent morbidity was $0 \%$. Of the two patients with symptomatic aneurysms, the symptoms were alleviated after treatment in one patient, and retreatment was necessary in one patient. In the review of the literature, comparisons were made in 69 large or giant aneurysms treated by coil embolization between those with and without indications for Pipeline. The additional treatment rate was significantly lower in the lesions with indications for Pipeline $(33.3 \%$ vs. $61.9 \%, P=0.02)$. The retreatment rate was significantly lower at $15.4 \%$, particularly in extradural aneurysms (Bouthillier $\mathrm{C} 4,5$ ).

Conclusion: The results of this study suggest that the retreatment rate after conventional coil embolization for extradural unruptured large cerebral aneurysms was not high and that coil embolization is worth considering for asymptomatic aneurysms at these sites $10-15 \mathrm{~mm}$ in diameter.

Keywords > large aneurysm, flow diverter, giant aneurysm, embolization

Department of Neurosurgery, National Disaster Medical Center, Tokyo, Japan

Received: December 19, 2016; Accepted: May 24, 2017 Corresponding author: Jiro Aoyama. Department of Neurosurgery, National Disaster Medical Center, 3256 Midori-cho, Tachikawa, Tokyo 190-0014, Japan Email: Jaoyama1217@gmail.com

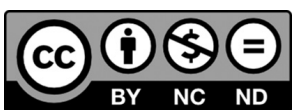

This work is licensed under a Creative Commons Attribution-NonCommercialNoDerivatives International License.

(C)2017 The Japanese Society for Neuroendovascular Therapy

\section{Introduction}

Treatments for large or giant aneurysm of the internal carotid artery (ICA) are classified into direct surgery and endovascular treatment. Direct surgery is often difficult depending on the anatomical characteristics of the site of the lesion (anterior clinoid process, cavernous sinus), ${ }^{1,2}$ and high morbidity and mortality have been reported.) Endovascular treatment has advantages over direct surgery including a low complication rate, but cases of incomplete occlusion and those requiring retreatment have been 
reported as problems. According to previous reports, retreatment has been needed after coil embolization in $5 \%-20 \%$ of all cerebral aneurysms. ${ }^{4-6)}$ However, in large or giant cerebral aneurysms, the initial complete occlusion rate has been reported to be $10 \%-68 \%$, the postoperative recanalization rate to be $56 \%-90 \%$, and retreatment rate to be $40 \%-50 \% .^{7-11)}$ In 2013 , flow diversion was reported to be effective for large or giant aneurysms of the ICA, ${ }^{12)}$ and it also began to be used in Japan in 2015. While it is expected to be effective, problems such as stenosis or occlusion of the device, rupture of aneurysms, and difficulty of device placement have been raised. For characterizing patients to whom flow diverters should be aggressively applied in the future, we evaluated problems with our past treatments and reviewed the literature for the characteristics and therapeutic outcomes of large and giant ICA aneurysms.

\section{Materials and Methods}

Of the 516 cerebral aneurysms treated at our hospital between July 2009 and May 2016, we reviewed those that were treated by coil embolization but are presently indications for treatment using Pipeline Flex (Medtronic, Irvine, CA, USA), that is, those that involved the petrous-superior hypophyseal segments of the ICA and were $10 \mathrm{~mm}$ or greater in diameter and $4 \mathrm{~mm}$ or greater in neck diameter. After excluding patients who developed subarachnoid hemorrhage (SAH) within 60 days, those who had intracranial hemorrhage or surgery within 42 days, those who showed coagulation disorder or thrombocytopenia, those who had previous stent placement for the aneurysm, those who were known to have allergy to platinum or cobalt, and those who had stenosis in the ipsilateral ICA, the treatment method, treatment effect, complication rate, and retreatment rate were studied in the remaining 10 patients.

Regarding statistical analysis, the age and follow-up period were examined by the t-test, and the other variables were examined by the $\chi^{2}$-test or Fisher's exact test, at the $\mathrm{P}<0.05$ level of significance.

\section{Review of the literature for the long-term results of coil embolization in large and giant aneurysms} PubMed was searched using "large," "giant," "cerebral aneurysm," and "recanalization" as keywords. Similar articles were also searched for related papers. Of the papers that we encountered, those that were about large or giant aneurysms treated by coil embolization and followed up by imaging modalities for 6 months or longer and provided
Table 1 Patient characteristics and therapeutic outcomes

\begin{tabular}{|c|c|}
\hline & 10 cases \\
\hline \multicolumn{2}{|l|}{ Sex } \\
\hline Male & $1(10 \%)$ \\
\hline Female & $9(90 \%)$ \\
\hline Age (year)* & $65.5 \pm 16.0$ \\
\hline Size of aneurysm $(\mathrm{mm})^{* *}$ & $\begin{array}{c}12.8 \\
(10.5-17.8)\end{array}$ \\
\hline \multicolumn{2}{|l|}{ Location } \\
\hline Cavernous & $3(30 \%)$ \\
\hline Ophthalmic & $2(20 \%)$ \\
\hline Superior hypophyseal artery & $5(50 \%)$ \\
\hline Asymptomatic unruptured aneurysm & $5(50 \%)$ \\
\hline Symptomatic unruptured aneurysm & $2(20 \%)$ \\
\hline $\begin{array}{l}\text { Disobliteration after embolization of } \\
\text { ruptured aneurysm }\end{array}$ & $3(30 \%)$ \\
\hline Follow-up period (month)* & $49.1 \pm 13.4$ \\
\hline \multicolumn{2}{|l|}{ Treatment } \\
\hline Balloon-assisted coil embolization & $8(80 \%)$ \\
\hline Stent-assisted coil embolization & $2(20 \%)$ \\
\hline Asymptomatic thromboembolic event & $5(50 \%)$ \\
\hline \multicolumn{2}{|l|}{ Symptomatic complication } \\
\hline delirium & $1(10 \%)$ \\
\hline Contrast-induced encephalopathy & $1(10 \%)$ \\
\hline Symptomatic thromboembolic event & $0(0 \%)$ \\
\hline Permanent morbidity & $0(0 \%)$ \\
\hline \multicolumn{2}{|l|}{ Symptoms } \\
\hline improvement & $1(50 \%)$ \\
\hline not improvement & $1(50 \%)$ \\
\hline Re-operation & $1(10 \%)$ \\
\hline
\end{tabular}

"Mean \pm standard deviation (SD); **mean (minimum-maximum).

details of the treated aneurysms were selected, and the patient characteristics (sex, age, site and size of the aneurysm, and follow-up period), results of the initial treatment, complication rate, and retreatment rate were compared between those with and without indications for Pipeline Flex.

\section{Results}

The patient characteristics and therapeutic outcomes are shown in Table 1. Of the patients treated at our hospital during the study period, 10 (one male and nine females) met the selection criteria. They consisted of five with asymptomatic unruptured aneurysms, two with symptomatic unruptured aneurysms, and three who had recanalization after treatment for ruptured aneurysms. Their mean age was $65.5 \pm 16.0$ years, the mean aneurysm size was $12.8 \mathrm{~mm}(10.5-17.8 \mathrm{~mm})$, and the mean follow-up period was $49.1 \pm 13.4$ months. The sites of the aneurysms were the cavernous segment in three patients, ophthalmic segment in two patients, and origin of the superior hypophyseal artery (SHA) in five patients. The treatments were balloon-assisted coil embolization in eight patients and stent-assisted coil embolization in two patients. After the 
treatment, asymptomatic ischemic lesions were noted in five patients on diffusion-weighted imaging (DWI) of MRI. Concerning symptomatic complications, postoperative delirium and contrast-induced encephalopathy were observed in one patient each. None of the patients showed symptomatic ischemic lesions, and the permanent morbidity was $0 \%$. The symptom observed in the two patients with symptomatic aneurysms was diplopia in both, and it was resolved after the treatment in one patient. One patient showed recanalization of the aneurysm and required additional treatment.

\section{Case presentation}

A 50-year-old woman visited the previous physician with sensory disturbance of the left parietal region and rightsided impairment of skilled motor activities as principal symptoms. She was suspected to have cerebral infarction on head MRI, referred to the neurology department of our hospital, and admitted for treatment. Close examination revealed a thrombosed aneurysm in the left ICA, and it was considered the source for emboli. She was referred to our department for further evaluation and treatment. On angiography, a large aneurysm with a maximum diameter of $17.8 \mathrm{~mm}$ and a neck diameter of $6.6 \mathrm{~mm}$ was noted at the ophthalmic segment of the left ICA (Fig. 1). After discussion with the patient, we decided to perform balloonassisted coil embolization. A 7 Fr sheath was placed in the right femoral artery, and a 7 Fr guiding catheter was coaxially inserted to the left ICA. To use the balloon-assisted technique, the Hyperglide $4 \mathrm{~mm} \times 10 \mathrm{~mm}$ (ev3, Plymouth, MN, USA) was ascended nearly to the neck of the aneurysm, and, after placing a microcatheter in the aneurysm, coil embolization was initiated. Framing was made using COSMOS-18 14 mm-51 cm (Terumo, Tokyo, Japan). Embolization was performed by gradually reducing the coil size and completed using a total of 17 coils. No major postoperative complication was observed, and the patient was discharged after 10 days. The patient has thereafter been followed up as an outpatient, but no recanalization has been noted until 52 months after the procedure (Fig. 2).

\section{Results of a literature review}

As a result of a review of the literature, 69 large or giant cerebral aneurysms reported in four papers (Gruber et al.,9) Sluzewski et al., ${ }^{13)} \mathrm{Li}$ et al., ${ }^{14)}$ and Hauck et al., ${ }^{15)}$ ) could be evaluated. The patient characteristics and therapeutic outcomes in the four papers and the present study are

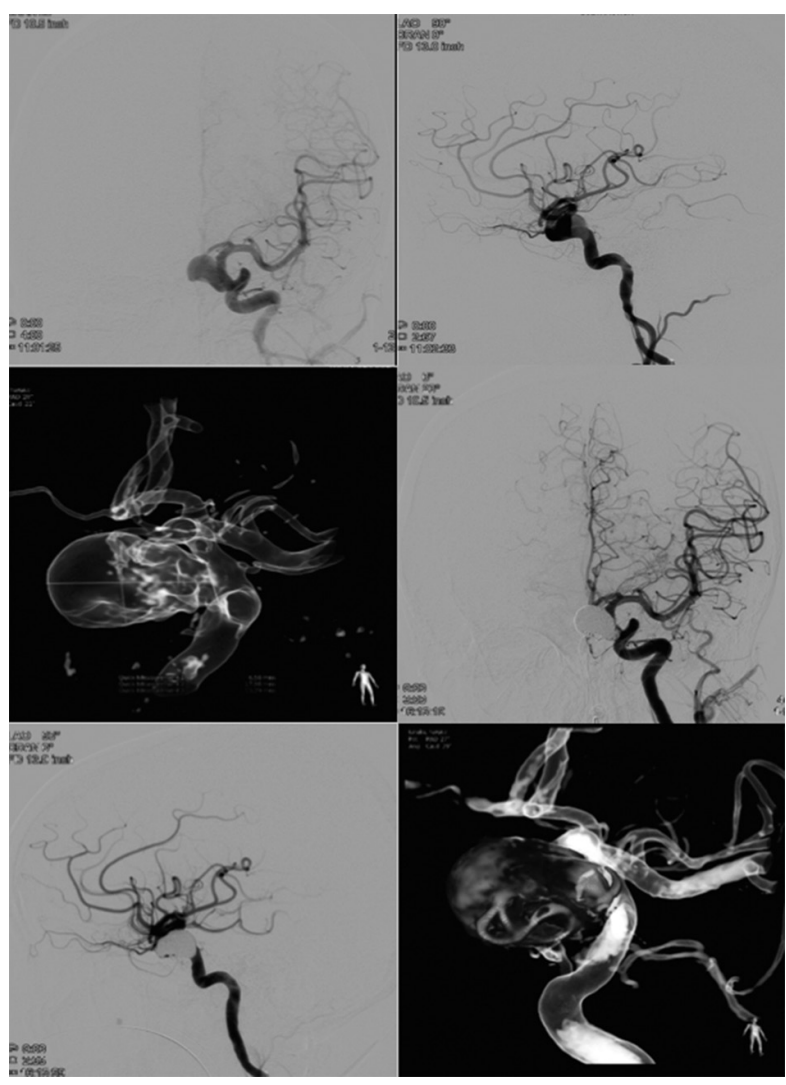

Fig. 1 Upper left: preoperative frontal view, upper right: preoperative lateral view, middle left: preoperative 3D composite image, middle right: postoperative frontal view, lower left: postoperative lateral view, lower right: postoperative 3D composite image. Coil embolization was performed by the balloon-assisted technique using a total of 17 coils.

summarized in Table 2. Next, concerning the results of coil embolization of aneurysms, the patient characteristics (sex, age, site and size of the aneurysm, and follow-up period), results of initial treatment, complication rate, and retreatment rate were compared between the lesions with and without indications for Pipeline Flex. The results are shown in Table 3. No significant difference was observed in sex, age, aneurysm size, or follow-up period between the two groups. Regarding the treatment methods, stent-assisted technique was used for $40.7 \%$ of the lesions with indications for Pipeline Flex but none of the other lesions. Procedural complications were observed in $11.1 \%$ of the lesions with indications for Pipeline and $19.0 \%$ of the other lesions, but the difference was not significant. However, the retreatment rate was $33.3 \%$ and $61.9 \%$, respectively, being significantly lower in those with indications for Pipeline $(P=0.027)$. One hypothesis for the lower additional treatment rate in the lesions with indications for Pipeline is considered to have been that recanalization due 


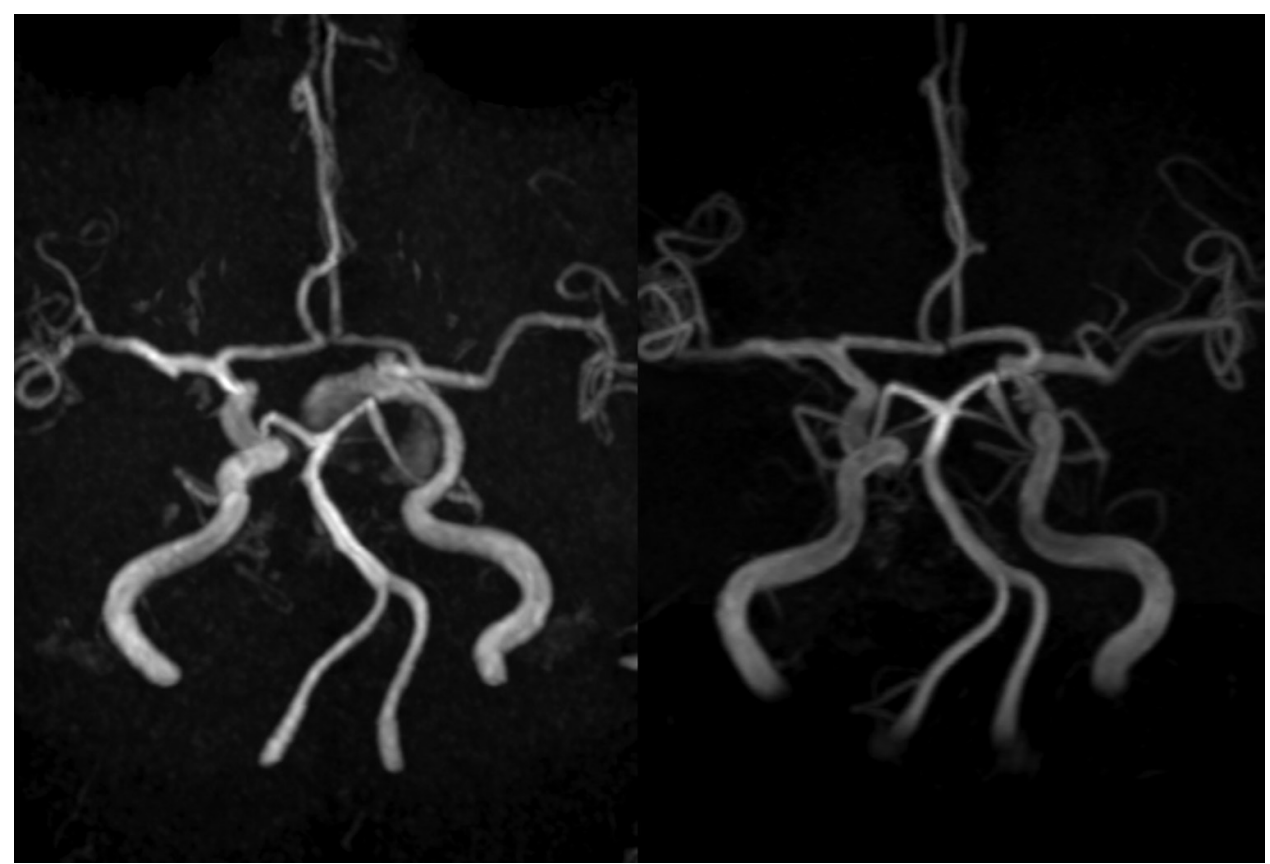

Fig. 2 Left: preoperative MRA, right: MRA 52 months postoperative. No clear recanalization is observed.

to expansion of the aneurysmal wall after treatment was less likely to occur in aneurysms in Bouthillier C4 and C5 segments, which are included in lesions with indications for Pipeline, as they are surrounded by the dura mater and bones. To verify this speculation, we compared extradural lesions (Bouthillier C4-5) and lesions at other sites. The results are shown in Table 4. No significant difference was observed in sex, age, aneurysm size, or follow-up period. The percentage of those treated by stent-assisted technique was significantly higher $(38.5 \%$ and $10.7 \%$; $=0.027)$, and the retreatment rate was significantly lower $(15.4 \%$ and $58.9 \% ; \mathrm{P}=0.006$ ), in extradural aneurysms.

\section{Discussion}

The results of surgical treatment for large aneurysms of the ICA at out hospital were satisfactory with a complication rate of $20 \%(2 / 10)$, additional treatment rate of $10 \%(1 / 10)$, and none suffering symptomatic ischemic complications or permanent morbidity. Retreatment was necessary in only one patient, who had a large aneurysm in the Bouthillier C6 segment. The complication and additional treatment rates after coil embolization for large cerebral aneurysms have been reported to be $6-7.5$ and $37 \%-47 \%$, respectively, ${ }^{16,17)}$ and the values at our hospital were lower. The results at our hospital were more favorable, probably because the mean size of the aneurysms treated by coil embolization was relatively small at $12.8 \mathrm{~mm}$. However, as only 10 patients were included in this study, we reviewed the literature to further evaluate the reason. When the results of conventional coil embolization in the 69 lesions reported in four papers were compared between those with and without indications for Pipeline Flex, the retreatment rate was significantly lower in those with indications for Pipeline Flex. We ascribed this to less frequent recanalization of extradural aneurysms (Bouthillier C4, 5) due to expansion of the aneurysmal wall after embolization. Comparison of extradural and intradural aneurysms showed that the retreatment rate was significantly lower in extradural aneurysms. However, in the lesions with indications for Pipeline, the retreatment rate was high (50\%; 7/14) after conventional coil embolization for large or giant aneurysms of the Bouthillier C6 segment, and this remains a problem to be addressed for the future.

However, as the papers reviewed in this study were published in 1999-2009 in a field with marked improvements in devices, and as stent-assisted coil embolization was performed only for lesions with indications for Pipeline Flex, attention to the possible bias is considered necessary.

In addition, reports concerning flow diverters are gradually increasing, including some related to long-term results. According to Kallmes et al., ${ }^{21)}$ who compiled the results of a total of 1221 aneurysms in 3 clinical studies concerning flow diverters, that is, Pipeline for Uncoilable or Failed Aneurysms (PUFS), ${ }^{18)}$ International Retrospective Study of 


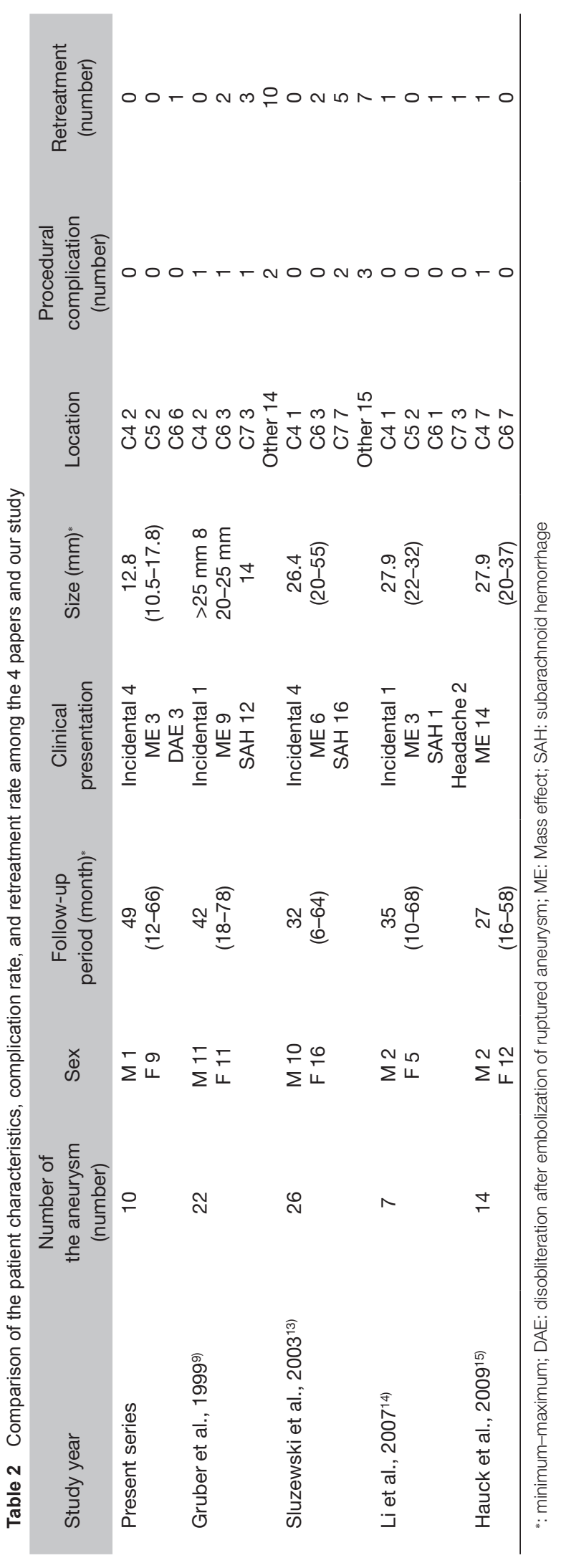

Pipeline Embolization Device (InterPED) ${ }^{19}$ ) and Aneurysm Study of Pipeline in an Observational Registry (ASPIRe), ${ }^{20)}$ the complete occlusion rate 1 year after flow diverter treatment of intra- and extradural large or giant ICA aneurysms was $85.5 \%$, and the retreatment rate during a follow-up period of $10.2 \pm 10.8$ months was $3.0 \%$. They also indicated the usefulness and safety of flow diverters, reporting that ischemic complications were observed in $3.7 \%$, hemorrhagic complications in $2.0 \%$, and death in $3.3 \%$ of the patients. From these results, they maintain that flow diverter treatment can be performed at lower recanalization and retreatment rates compared with conventional coil embolization and a sufficiently tolerable complication rate.

We also reviewed the outcomes of surgical and endovascular treatments by restricting the target lesions to extradural ICA aneurysms. Concerning the results of surgical treatment and coil embolization in 86 patients with aneurysms of the cavernous segment, Rooji et al. ${ }^{22}$ reported that the symptomatic complication rate was $2 \%$ $(1 / 50)$ and the retreatment rate was $0 \%(0 / 50)$ after ICA occlusion without bypass, that they were both $0 \%(0 / 5)$ after ICA occlusion with bypass, and that they were $0 \%$ $(0 / 31)$ and $19.4 \%$ (6/31), respectively, after coil embolization, with the retreatment rate being higher after coil embolization. van der Schaaf et al. ${ }^{23)}$ reported a systematic review of the results of treatment for aneurysms of the cavernous segment, according to which the symptomatic complication rate was $1.4 \%$ after coil embolization but $5 \%$ after ICA occlusion with/without bypass, suggesting the safety of coil embolization. Menon et al. ${ }^{24)}$ reported that the mortality and morbidity were both $8.3 \%$ after extracranial-intracranial (EC-IC) bypass for aneurysms of the cavernous segment. However, the formation of de novo cerebral aneurysms has been reported as a complication specific to internal carotid (IC) occlusion. This complication reportedly occurs in $4 \%-11 \%$ of the patients undergoing IC occlusion, ${ }^{25-28)}$ and this must be considered in the selection of treatment. Moreover, there have recently been a few reports on the results of treatment of extradural ICA aneurysms using flow diverters. Puffer et al. ${ }^{29)}$ reported that some complication occurred in $36 \%$ of 44 patients with cavernous carotid artery aneurysms and that surgery was necessary in $6.8 \%$ (vascular surgery associated with subcutaneous hematoma in $4.5 \%$ and endovascular treatment for in-stent stenosis in 2.3\%). In addition, Briganti et al. ${ }^{30)}$ reported that the mortality after flow diverter treatment of lesions at the same site was $4 \%$. While simple comparison of these results is not approved, they suggest 
Table 3 Comparison of the patient characteristics, complication rate, and retreatment rate of $\mathrm{C} 4,5,6$ (with indications for Pipeline Flex) vs. other (without indications for Pipeline Flex) lesions

\begin{tabular}{|c|c|c|c|}
\hline & $\begin{array}{c}C 4,5,6 \\
27 \text { cases }\end{array}$ & $\begin{array}{l}\text { Others } \\
42 \text { cases }\end{array}$ & $P$ value \\
\hline \multicolumn{4}{|l|}{ Sex } \\
\hline Male & 5 & 20 & $P=0.021$ \\
\hline Female & 22 & 22 & \\
\hline Age (year)* & $56 \pm 14.9$ & $50 \pm 9.1$ & $P=0.954$ \\
\hline \multicolumn{4}{|l|}{ Size } \\
\hline giant (>25 mm) & 14 & 17 & $P=0.458$ \\
\hline Very large (20-25 mm) & 13 & 25 & \\
\hline \multicolumn{2}{|l|}{ Treatment } & $23.3 \pm 16.7$ & $P=0.543$ \\
\hline coil & 16 & 42 & $P<0.0001$ \\
\hline Stent/coil & 11 & 0 & \\
\hline Procedural complication & $\begin{array}{c}3 \\
(11.1 \%)\end{array}$ & $\begin{array}{c}8 \\
(19.0 \%)\end{array}$ & $P=0.508$ \\
\hline Retreatment & $\begin{array}{c}9 \\
(33.3 \%)\end{array}$ & $\begin{array}{c}26 \\
(61.9 \%)\end{array}$ & $P=0.027$ \\
\hline
\end{tabular}

$*: \pm$ standard deviation (SD)

Table 4 Comparison of the patient characteristics, complication rate, and retreatment rate of

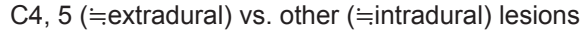

\begin{tabular}{|c|c|c|c|}
\hline & $\begin{array}{c}\text { C4, } 5 \text { ( } \fallingdotseq \text { extradural) } \\
13 \text { cases }\end{array}$ & $\begin{array}{c}\text { Others }(\fallingdotseq \text { intradural) } \\
56 \text { cases }\end{array}$ & $P$ value \\
\hline \multicolumn{4}{|l|}{ Sex } \\
\hline Male & 3 & 22 & $P=0.349$ \\
\hline Female & 10 & 34 & \\
\hline Age (year)* & $52 \pm 16.0$ & $52 \pm 11.0$ & $P=0.221$ \\
\hline \multicolumn{4}{|l|}{ Size } \\
\hline giant (>25 mm) & 6 & 25 & $P=1.000$ \\
\hline Very large (20-25 mm) & 7 & 31 & \\
\hline Follow-up period (month)* & $25.5 \pm 17.7$ & $24.0 \pm 16.2$ & $P=0.228$ \\
\hline \multicolumn{4}{|l|}{ Treatment } \\
\hline coil & 8 & 50 & $P=0.027$ \\
\hline Stent/coil & 5 & 6 & \\
\hline Procedural complication & $\begin{array}{c}2 \\
(15.4 \%)\end{array}$ & $\begin{array}{c}9 \\
(16.0 \%)\end{array}$ & $P=1.000$ \\
\hline Retreatment & $\begin{array}{c}2 \\
(15.4 \%)\end{array}$ & $\begin{array}{c}33 \\
(58.9 \%)\end{array}$ & $P=0.006$ \\
\hline
\end{tabular}

$*: \pm$ standard deviation (SD)

the possibility that coil embolization can be performed for extradural internal carotid aneurysms with a lower complication rate compared with other treatments.

A problem with conventional coil embolization is the care for patients with cranial nerve palsy (CNP). We encountered two patients with CNP at our hospital, and one of them showed no improvement in symptoms after treatment. It has been reported that the symptomatic improvement was observed after coil embolization of large or giant aneurysms in $38 \%-46 \%$ of the patients with CNP. ${ }^{9,31)}$ However, Goldenberg-Choen et al. ${ }^{32)}$ reported that symptoms were alleviated in none and exacerbated in 7 of the 10 patients who underwent coil embolization for symptomatic large aneurysms of the cavernous segment. On the other hand, there has been a report that the symptomatic improvement rate in patients with CNP was 64\% after treatment using Pipeline, ${ }^{33)}$ and it tended to be higher in those treated using Pipeline.

The number of patients treated at our hospital is small, and generalization of the results is not warranted, but they suggest the possibility that aneurysms in the Bouthillier C4 and C5 segments without CNP can be treated with a low complication rate and a relatively low retreatment rate by the current coil embolization procedure. However, it is recommended to consider Pipeline for patients with CNP, and the aggressive use of Pipeline should be evaluated for Bouthillier C6 aneurysms because the retreatment rate is high, and the occurrence or exacerbation of visual loss due to optic nerve compression is possible, after coil embolization. In the application of Pipeline to such cases, a combination with coil embolization may be useful because cases 
of subacute rupture of aneurysms after treatment with Pipeline alone have been reported.

Limitations of the present study include that it was a retrospective study that the number of patients encountered at our hospital was small, that the mean size of the aneurysms treated at our hospital was relatively small at $12.8 \mathrm{~mm}$ as there were no giant aneurysms, and that the papers reviewed were published in 1999-2009 and may not reflect the latest trend. Further evaluation with accumulation of cases is considered necessary.

\section{Conclusion}

The results of treatment for large aneurysms of the petrousSHA segments were as follows: the symptomatic ischemic complication rate was $0 \%$, permanent morbidity was $0 \%$, retreatment rate was $10 \%$, and CNP improvement rate was $50 \%$. Despite the small number of patients, aneurysms of the Bouthillier C4 and C5 segments could be treated with a low retreatment rate, and conventional coil embolization was suggested to be sufficiently worth considering even if large unruptured extradural aneurysms about $10-15 \mathrm{~mm}$ in diameter are indications for flow diverters.

\section{Disclosure Statement}

Neither the first author nor any of the coauthors have any conflicts of interest.

\section{References}

1) Colli BO, Carlotti CG Jr, Assirati JA Jr, et al: Results of microsurgical treatment of paraclinoid carotid aneurysms. Neurosurg Rev 2013; 36: 99-114; discussion 114-115.

2) Kumon Y, Sakaki S, Kohno K, et al: Asymptomatic, unruptured carotid-ophthalmic artery aneurysms: angiographical differentiation of each type, operative results, and indications. Surg Neurol 1997; 48: 465-472.

3) Sun Y, Li Y, Li AM: Endovascular treatment of paraclinoid aneurysms. Interv Neuroradiol 2011; 17: 425-430.

4) Ferns SP, Sprengers ME, van Rooij WJ, et al: Coiling of intracranial aneurysms: a systematic review on initial occlusion and reopening and retreatment rates. Stroke 2009; 40: e523-e529.

5) Molyneux AJ, Kerr RS, Birks J, et al: Risk of recurrent subarachnoid haemorrhage, death, or dependence and standardised mortality ratios after clipping or coiling of an intracranial aneurysm in the International Subarachnoid Aneurysm Trial (ISAT): long-term follow-up. Lancet Neurol 2009; 8: 427-433.
6) Campi A, Ramzi N, Molyneux AJ, et al: Retreatment of ruptured cerebral aneurysms in patients randomized by coiling or clipping in the International Subarachnoid Aneurysm Trial (ISAT). Stroke 2007; 38: 1538-1544.

7) Wang B, Gao BL, Xu GP, et al: Endovascular embolization is applicable for large and giant intracranial aneurysms: experience in one center with long-term angiographic followup. Acta Radiol 2015; 56: 105-113.

8) Mordasini P, Schroth G, Guzman R, et al: Endovascular treatment of posterior circulation cerebral aneurysms by using Guglielmi detachable coils: a 10-year single-center experience with special regard to technical development. AJNR Am J Neuroradiol 2005; 26: 1732-1738.

9) Gruber A, Killer M, Bavinzski G, et al: Clinical and angiographic results of endosaccular coiling treatment of giant and very large intracranial aneurysms: a 7-year, single-center experience. Neurosurgery 1999; 45: 793-803; discussion 803-804.

10) Li MH, Gao BL, Fang C, et al: Angiographic follow-up of cerebral aneurysms treated with Guglielmi detachable coils: an analysis of 162 cases with 173 aneurysms. AJNR Am J Neuroradiol 2006; 27: 1107-1112.

11) Mohammadian R, Asgari M, Sattarnezhad N, et al: Endovascular treatment of very small and very large ruptured aneurysms of the anterior cerebral circulation: a single-center experience. Cerebrovasc Dis 2013; 35: 235-240.

12) Becske T, Kallmes DF, Saatci I, et al: Pipeline for uncoilable or failed aneurysms: results from a multicenter clinical trial. Radiology 2013; 267: 858-868.

13) Sluzewski M, Menovsky T, van Rooij WJ, et al: Coiling of very large or giant cerebral aneurysms: long-term clinical and serial angiographic results. AJNR Am J Neuroradiol 2003; 24: 257-262.

14) Li MH, Li YD, Fang C, et al: Endovascular treatment of giant or very large intracranial aneurysms with different modalities: an analysis of 20 cases. Neuroradiology 2007; 49: 819-828.

15) Hauck EF, Welch BG, White JA, et al: Stent/coil treatment of very large and giant unruptured ophthalmic and cavernous aneurysms. Surg Neurol 2009; 71: 19-24; discussion 24.

16) Di Maria F, Pistocchi S, Clarençon F, et al: Flow diversion versus standard endovascular techniques for the treatment of unruptured carotid-ophthalmic aneurysms. AJNR Am J Neuroradiol 2015; 36: 2325-2330.

17) Chalouhi N, Jabbour P, Singhal S, et al: Stent-assisted coiling of intracranial aneurysms: predictors of complications, recanalization, and outcome in 508 cases. Stroke 2013; 44: 1348-1353.

18) Becske T, Kallmes DF, Saatci I, et al: Pipeline for uncoilable or failed aneurysms: results from a multicenter clinical trial. Radiology 2013; 267: 858-868. 
19) Kallmes DF, Hanel R, Lopes D, et al: International retrospective study of the pipeline embolization device: a multicenter aneurysm treatment study. AJNR Am J Neuroradiol 2015; 36: 108-115.

20) Kallmes DF, Brinjikji W, Boccardi E, et al: Aneurysm Study of Pipeline in an Observational Registry (ASPIRe). Interv Neurol 2016; 5: 89-99.

21) Kallmes DF, Brinjikji W, Cekirge S, et al: Safety and efficacy of the Pipeline embolization device for treatment of intracranial aneurysms: a pooled analysis of 3 large studies. J Neurosurg 2016; 28: 1-6.

22) van Rooij WJ: Endovascular treatment of cavernous sinus aneurysms. AJNR Am J Neuroradiol 2012; 33: 323-326.

23) van der Schaaf IC, Brilstra EH, Buskens E, et al: Endovascular treatment of aneurysms in the cavernous sinus: a systematic review on balloon occlusion of the parent vessel and embolization with coils. Stroke 2002; 33: 313-318.

24) Menon G, Jayanand S, Krishnakumar K, et al: EC-IC bypass for cavernous carotid aneurysms: An initial experience with twelve patients. Asian J Neurosurg 2014; 9: 82-88.

25) Dyste GN, Beck DW: De novo aneurysm formation following carotid ligation: case report and review of the literature. Neurosurgery 1989; 24: 88-92.

26) Arambepola PK, McEvoy SD, Bulsara KR: De novo aneurysm formation after carotid artery occlusion for cerebral aneurysms. Skull Base 2010; 20: 405-408.
27) Tomsick T: Long-term clinical follow-up of therapeutic internal carotid artery occlusion. AJNR 2007; 28: 1626.

28) Arnaout OM, Rahme RJ, Aoun SG, et al: De novo large fusiform posterior circulation intracranial aneurysm presenting with subarachnoid hemorrhage 7 years after therapeutic internal carotid artery occlusion: case report and review of the literature. Neurosurgery 2012; 71: E764-E771.

29) Puffer RC, Piano M, Lanzino G, et al: Treatment of cavernous sinus aneurysms with flow diversion: results in 44 patients. AJNR Am J Neuroradiol 2014; 35: 948-951.

30) Briganti F, Napoli M, Tortora F, et al: Italian multicenter experience with flow-diverter devices for intracranial unruptured aneurysm treatment with periprocedural complications - a retrospective data analysis. Neuroradiology 2012; 54: 1145-1152.

31) Heran NS, Song JK, Kupersmith MJ, et al: Large ophthalmic segment aneurysms with anterior optic pathway compression: assessment of anatomical and visual outcomes after endosaccular coil therapy. J Neurosurg 2007; 106: 968-975.

32) Goldenberg-Cohen N, Curry C, Miller N, et al: Long term visual and neurological prognosis in patients with treated and untreated cavernous sinus aneurysms. J Neurol Neurosurg Psychiatry 2004; 75: 863-867.

33) Sahlein DH, Fouladvand M, Becske T, et al: Neuroophthalmological outcomes associated with use of the Pipeline Embolization Device: analysis of the PUFS trial results. J Neurosurg 2015; 123: 897-905. 